\title{
How Intermediate Capacity Modes Provide Accessibility and Resilience in Metropolitan Transit Networks: Insights from a Global Study of 19 Cities
}

\author{
Dr. Jan Scheurer
}

Curtin University, Perth and RMIT University, Melbourne/Barcelona

\begin{abstract}
Drawing on the Spatial Network Analysis of Multimodal Urban Transport Systems (SNAMUTS) accessibility tool, this paper introduces comparative results of public transport network performance measures in 19 metropolitan regions in developed countries. These results are assessed typologically and functionally to highlight the contribution of each common public transport mode to maximize (or not) the integration of transport networks with the urban structure to optimize accessibility outcomes. It is shown that the capacity and performance spectrum embodied by each mode represents a gradual scale that allocates a specific niche to intermediate modes, particularly trams that are present in half the cities studied and absent from the others.

In a comparison of Munich, Germany, where a full spectrum of public transport modes is present, and Hamburg, Germany, where there is a performance gap between heavy rail and buses, accessibility outcomes are discussed. Alongside "alternative history" scenarios concerning the hypothetical retention of trams in Hamburg and full closure of the system in Munich, it is shown that the absence of an intermediate mode in Hamburg's actual network has a significant detrimental effect on the resilience of the public transport system compared to its Bavarian counterpart as well as to other international cities.
\end{abstract}

Key words: Accessibility, land use-transport integration, network analysis, trams

\section{Introduction}

Public transport networks in Western cities have developed over time under varying regimes of city building traditions, infrastructure provision, governance arrangements, and policy priorities regarding the importance afforded to collective modes of 
transport. One of the results of this historically-grown divergence in policy and practice is that different cities now find themselves with differing ranges of modes making up their public transport systems. In a spatial accessibility study on a sample of 23 cities on 4 continents, 19 of which are discussed in this paper, it was found that the provision of rail modes, in particular, follows no uniform template. Many cities abandoned at least part of their tram operations in the early post-WWII period, but there are notable exceptions as well as examples where the mode was reintroduced some decades later. A majority of North American cities gave up on rail-based public transport altogether for a period after 1945. Elsewhere, many cities made a concerted effort to adapt their mainline rail networks to the needs of suburban passenger travel, although the outcomes vary greatly in terms of network density and service levels. Some cities introduced new underground metro systems or upgraded and expanded existing operations, and others rejected such a move as not worth the substantial investment required in the face of leaner and perhaps more effective alternatives for improving public transport. Although buses represent a ubiquitous transport mode that can be found in each of the 19 case study cities, the configuration of their networks and the deployment of services once again illustrate a raft of differing priorities between the cities in the sample.

The varying technical and economic performance characteristics of the different public transport modes have been widely documented in the literature and in practice reviews (for a thorough discussion, see, for example, Hass-Klau et al. 2003; Griffin 2005; Vuchic 2005; Van der Bijl and Van Oort 2014). In contrast, this paper explores and attempts to categorize such differences with a view to investigating their impact on accessibility outcomes. For this purpose, a limited range of comparative accessibility indicators from the Spatial Network Analysis for Multimodal Urban Transport Systems (SNAMUTS) toolbox is introduced (Scheurer and Curtis 2016), namely the operational input into the sub-networks of each transport mode in each city (service intensity), the proportional importance of each mode in facilitating travel opportunities across the network (betweenness centrality), and the occurrence of under- or over-utilization of a mode's potential as expressed by its ability to meet this level of importance (network resilience). Essentially, we are interested in whether public transport networks with modes of intermediate capacity and performance, particularly trams, as the most widespread such mode in the sample, have been able to optimize accessibility outcomes for public transport networks as a whole and enhance their capacity to absorb current or future growth in passenger numbers.

The first part of this paper provides an overview of the differences and similarities between cities in providing (or not) each of the key modes suburban rail, metro/light rail (LRT), tram, and bus and the roles that these modes take up in the transport mix of their host city. In the second part, the accessibility and network resilience effects of a hypothetically-modified modal balance in two case study cities, Hamburg and Munich, Germany, are tested. A brief reflection on the circumstances in which cities can address the shortfalls identified in the analysis and on the role that accessibility tools such as SNAMUTS can play in assisting this process, follows in conclusion. 


\section{Modal Range of Public Transport Systems-An Overview}

Table 1 provides an overview of the public transport modes available in each of 19 Australasian, North American, and European case study cities. For the rail modes, it also provides a rough categorization of the degree of network consolidation: does the mode consist only of a starter line (single route), does it consist of more than one route but covers only a minority of a city's key transport corridors (selected corridors), does it cover a majority of them while leaving some gaps (multiple corridors), or does it cover practically all of them (mature expansion)? In the North American case study cities, suburban rail systems are characterized by limited operation spans, in some cases only during weekday peak hours in the peak direction. Elsewhere, "low frequency" should be understood as typical weekday daytime frequencies of 30 minutes, "medium frequency" as 15 or 20 minutes, and "high frequency" as 10 minutes or better. Metro and light rail systems generally fall into the medium- to high-frequency category everywhere, for which reason their service frequencies are not explicitly specified. In some cities, notably Portland, Seattle, Oporto, and (partially) Amsterdam, light rail networks have been listed under the "metro" category since these systems share many performance characteristics (multiple-unit vehicles and segregated, prioritized alignments) with heavy rail. However, these systems also contain some on-street running, and it is acknowledged that this circumstance reduces their average speed in some instances and, thus, limits their performance compared to fully grade-separated urban rail technology.

Tram networks are categorized by "first generation" and "second generation," with the former term depicting systems that have been in operation continuously since their inception in the era before mass motorization (generally in the late $19^{\text {th }}$ or early $20^{\text {th }}$ centuries), and the latter term describing systems that have been reintroduced to their host cities more recently (1980s or later) after a period when trams were absent. In Seattle and Portland, the term "tram" is applied to these cities' streetcar systems, built during the 2000s primarily to access and attract property investment to inner city redevelopment areas. In other cities, first generation tram systems have survived only as heritage operations on specific lines (Barcelona, Oporto) or were reintroduced as such (Vancouver, Auckland), using historic vehicles. These systems are not further discussed in this analysis, since they usually cater exclusively to the tourist and recreational market and do not form an integral part of or accept the fares of the regular public transport network. 
TABLE 1. Overview of Presence and Key Characteristics of Public Transport Modes in 19 Case Study Cities

\begin{tabular}{|c|c|c|c|c|c|}
\hline City & Suburban Rail & Metro & Tram & Bus & Other \\
\hline Adelaide & $\begin{array}{l}\text { Selected corridors; low } \\
\text { frequency }\end{array}$ & None & $\begin{array}{l}\text { First generation; } \\
\text { single corridor }\end{array}$ & $\begin{array}{c}\text { Radial core city coverage; single BRT } \\
\text { corridor }\end{array}$ & \\
\hline Auckland & $\begin{array}{l}\text { Selected corridors; low } \\
\text { frequency }\end{array}$ & None & Heritage only & $\begin{array}{c}\text { Selected radial core city coverage; single } \\
\text { BRT corridor }\end{array}$ & Ferry routes \\
\hline Brisbane & $\begin{array}{l}\text { Selected corridors; low } \\
\text { frequency }\end{array}$ & None & None & $\begin{array}{c}\text { Selected radial core city coverage; } \\
\text { selected BRT corridors }\end{array}$ & Ferry routes \\
\hline Melbourne & $\begin{array}{l}\text { Multiple corridors; } \\
\text { medium frequency }\end{array}$ & None & $\begin{array}{l}\text { First generation; } \\
\text { mature expansion }\end{array}$ & Selected corridors, mostly orbital & \\
\hline Perth & $\begin{array}{l}\text { Multiple corridors; } \\
\text { medium frequency }\end{array}$ & None & None & $\begin{array}{l}\text { Selected radial core city coverage; } \\
\text { selected suburban corridors }\end{array}$ & Ferry route \\
\hline Sydney & $\begin{array}{l}\text { Multiple corridors; } \\
\text { medium frequency }\end{array}$ & None & $\begin{array}{l}\text { Second generation; } \\
\text { single corridor }\end{array}$ & $\begin{array}{c}\text { Mature core city coverage; selected } \\
\text { suburban corridors, some BRT }\end{array}$ & Ferry routes \\
\hline Montreal & $\begin{array}{l}\text { Selected corridors; low } \\
\text { frequency, limited span }\end{array}$ & Multiple corridors & None & Mature core city coverage & \\
\hline Portland & Marginal & $\begin{array}{l}\text { Multiple corridors } \\
\text { (LRT) }\end{array}$ & $\begin{array}{l}\text { Second generation; } \\
\text { selected inner urban } \\
\text { redevelopment areas }\end{array}$ & Mature core city coverage & \\
\hline Seattle & Marginal & $\begin{array}{l}\text { Single corridor } \\
\quad(\text { LRT) }\end{array}$ & $\begin{array}{l}\text { Second generation; } \\
\text { single inner urban } \\
\text { redevelopment area }\end{array}$ & $\begin{array}{l}\text { Selected core city coverage and } \\
\text { corridors; some trolleybus lines }\end{array}$ & \\
\hline Vancouver & Marginal & $\begin{array}{c}\text { Multiple corridors; } \\
\text { driverless }\end{array}$ & Heritage only & $\begin{array}{c}\text { Mature core city coverage and suburban } \\
\text { corridors; some trolleybus lines }\end{array}$ & Ferry route \\
\hline Amsterdam & $\begin{array}{l}\text { Multiple corridors; } \\
\text { medium frequency }\end{array}$ & Selected corridors & $\begin{array}{l}\text { First generation } \\
\text { Mature expansion }\end{array}$ & $\begin{array}{c}\text { Mature core city and suburban coverage } \\
\text { in conjunction with trams; selected BRT } \\
\text { corridors }\end{array}$ & Ferry routes \\
\hline Barcelona & $\begin{array}{l}\text { Multiple corridors; } \\
\text { medium frequency }\end{array}$ & Mature expansion & $\begin{array}{l}\text { Second generation } \\
\text { Selected corridors }\end{array}$ & $\begin{array}{l}\text { Mature core city coverage; selected } \\
\text { suburban coverage }\end{array}$ & Cable cars \\
\hline Edinburgh & $\begin{array}{l}\text { Selected corridors; } \\
\text { medium to low } \\
\text { frequency }\end{array}$ & $\begin{array}{l}\text { Single corridor } \\
\text { (LRT) opened } \\
2014 \text { (post- } \\
\text { analysis) }\end{array}$ & None & $\begin{array}{l}\text { Mature core city coverage; selected } \\
\text { suburban corridors }\end{array}$ & \\
\hline Hamburg & $\begin{array}{l}\text { Multiple corridors; high } \\
\text { frequency }\end{array}$ & Multiple corridors & None & $\begin{array}{l}\text { Mature core city coverage; selected } \\
\text { suburban corridors }\end{array}$ & Ferry routes \\
\hline Copenhagen & $\begin{array}{l}\text { Mature expansion; high } \\
\text { frequency }\end{array}$ & $\begin{array}{c}\text { Selected corridors; } \\
\text { driverless }\end{array}$ & None & Mature core city and suburban coverage & Ferry route \\
\hline Munich & $\begin{array}{l}\text { Mature expansion; } \\
\text { medium frequency }\end{array}$ & Mature expansion & $\begin{array}{l}\text { First generation } \\
\text { Multiple corridors }\end{array}$ & $\begin{array}{l}\text { Mature core city coverage in } \\
\text { conjunction with trams }\end{array}$ & \\
\hline Oporto & $\begin{array}{l}\text { Selected corridors; } \\
\text { medium to low } \\
\text { frequency }\end{array}$ & $\begin{array}{l}\text { Multiple corridors } \\
\text { (LRT) }\end{array}$ & Heritage only & $\begin{array}{l}\text { Mature core city coverage; selected } \\
\text { suburban corridors }\end{array}$ & Cable car \\
\hline Vienna & $\begin{array}{l}\text { Multiple corridors; high } \\
\text { to medium frequency }\end{array}$ & Mature expansion & $\begin{array}{l}\text { First generation; } \\
\text { mature expansion }\end{array}$ & $\begin{array}{c}\text { Mature core city coverage in } \\
\text { conjunction with trams }\end{array}$ & \\
\hline Zurich & $\begin{array}{l}\text { Mature expansion; } \\
\text { medium frequency }\end{array}$ & None & $\begin{array}{l}\text { First generation; } \\
\text { mature expansion }\end{array}$ & $\begin{array}{c}\text { Mature core city and suburban coverage } \\
\text { in conjunction with trams; some } \\
\text { trolleybus lines }\end{array}$ & $\begin{array}{l}\text { Ferry } \\
\text { routes, } \\
\text { cable cars }\end{array}$ \\
\hline
\end{tabular}


For buses, the categorization is limited to those parts of the networks that meet the SNAMUTS minimum service standard, which requires a weekday daytime service frequency of 20 minutes or better and a weekend daytime service frequency of 30 minutes or better. In many cities, this procedure focuses our attention on a cohort of core routes. Do these form a predominantly or exclusively radial network? If so, are the radial corridors spaced in a way that enables walkable access to at least one corridor within a maximum 400-meter distance from anywhere (full coverage), or are there spatial gaps between these walkable catchments (selected coverage)? Does the network consist of lines in different directions - radial, orbital, and perhaps diagonal (mature expansion)? Do these characteristic apply only to the core city (in most European and North American cities, the central municipality; in others, roughly the outline of the pre-1945 city expansion), or do they extend further into suburban areas? In some cities, notably Amsterdam, Munich, Vienna, and Zurich, a mature surface network structure is achieved primarily through the interplay of bus and tram routes; this is also noted. Last, in some cities, specific (segregated and prioritized) bus rapid transit (BRT) infrastructure has been provided to some corridors to boost performance and capacity. The most expansive such network among our 19 case study cities can be found in Brisbane, but BRT lines also are present in Auckland, Adelaide, Sydney, and Amsterdam. 
FIGURE 1.

Geographical location of case study cities in Australasia, Europe, and North America
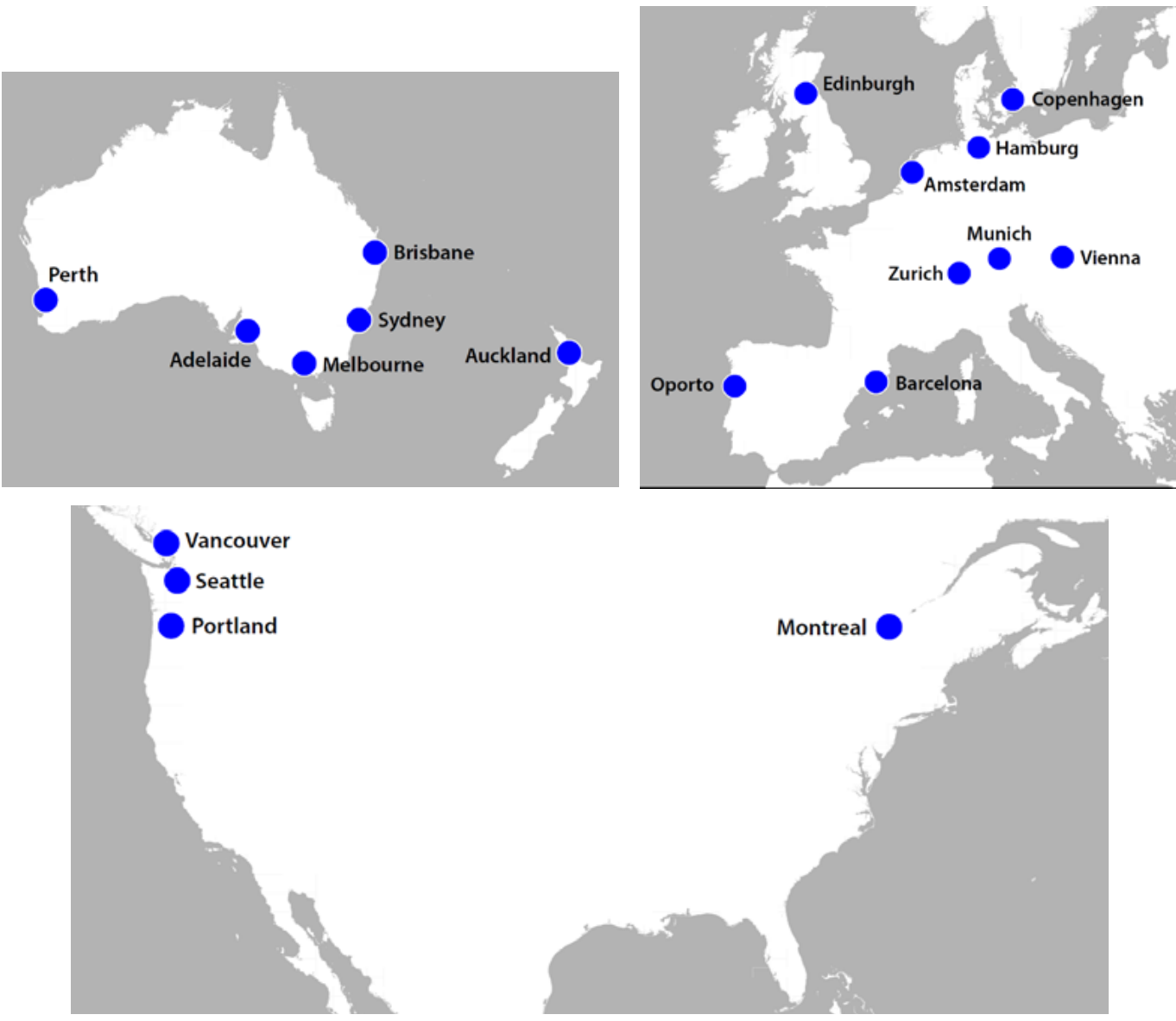

\section{Role of Trams in Case Study Cities}

This section highlights the role of trams as an intermediate-capacity transport mode that is present in approximately half the case study cities in the sample. As mentioned above, the characteristics of tram systems differ across these cities. Our focus is on operations that are predominantly aligned at surface level within public road reserves (with or without track reservation) and largely operated by single-unit contemporary vehicles. This applies to the systems in Europe and Melbourne and the streetcar lines in Seattle and Portland. It partially applies to the tram operations in Sydney and Adelaide, which feature similar characteristics in terms of vehicle capacity but have a greaterthan-50\% share of off-street reservations.

Qualitative correlations are drawn between the presence, expansion, and configuration of tram networks in each of these cities, identifying some key parameters of accessibility performance. For this purpose, we draw on three SNAMUTS measures. For more detail on the origins and methodology of the tool, readers are advised to consult Curtin and Scheurer (2016) or the project website at www.snamuts.com.

Service intensity depicts the number of vehicles or train sets in simultaneous revenue service during the weekday inter-peak period that are required to operate the 
proportion of the network that meets the SNAMUTS minimum service standard (30-minute frequencies or better for suburban rail, metro/LRT, or ferries; 20-minute frequencies or better for trams and buses), expressed relative to metropolitan population (vehicles per 100,000 residents). It is an indicator for the level of operational input that a city's decisionmakers appear willing and capable of supplying towards its public transport service. High figures can be read as a measure of largesse in this context; however, particularly for surface modes, they can also speak of inefficiencies accrued in the operation of smaller than necessary vehicles at slower than desirable speeds.

Service intensity deliberately does not differentiate between modes of different passenger capacity, as it is interested primarily in quantifying movement opportunities from the perspective of the user (e.g., a six-car train can carry a multiple of the passengers of a standard bus, but both modes provide one movement opportunity per departure in space and time).

Segmental betweenness counts the proportion of travel opportunities created by a city's land use-transport system that are attracted to the mode in question. Travel opportunities are defined as potential trip relations between concentrations of residents and jobs in a metropolitan area, moderated by their spatial separation or travel impediment, which, in turn, is composed of travel time and service frequency on public transport. Each trip relation between a matrix of activity nodes is allocated a preferred network path (by taking in the factors of travel impediment, transfer intensity, and travel time), and these network paths are traced to route segments of each mode. The figures can tell us how important a particular transport mode is in facilitating movement between activities in a metropolitan area and whether or not this level of importance appears commensurate with the network characteristics assessed qualitatively in the previous section or to the position of the mode in the transport mix of the city in question.

The concept of betweenness centrality as a network measure first appeared in the literature in Freeman (1977) and is discussed in detail by Koschützki et al. (2005) and Porta et al. (2006). It has been modified specifically to suit the purpose of analysing public transport networks (Scheurer et al. 2007).

Network resilience utilizes the segmental betweenness results on each network element and extracts their ratio with the actual passenger capacity offered, which varies by service frequency, transport mode, and operational practice (e.g., how many carriages a suburban train has, on average). It can provide us with an idea whether or not a transport mode is equipped to handle the tasks allocated to it by the configuration of the land use-transport system and to what extent it is in a position to absorb further patronage growth as land uses increase and consolidate and/or as public transport's role in the urban mobility market strengthens. This measure picks up on the concept of stress centrality first mentioned in the literature by Shimbel (1953). In this adaptation, positive figures indicate resilience, and negative figures depict mounting stress/ vulnerability. Generally, the measure has been calibrated to mark a cause for concern for levels below zero, and a crisis point for levels below -30. Note, however, that poor 
network resilience does not necessarily equate to actual overcrowding of a service; it can just as well be indicative of a degree of "latent demand" across the network or along particular corridors that public transport, for a variety of reasons, fails to pick up.

Table 2 shows that the tram systems in the sample differ quite significantly in character and history. In some cases, this is due to periods of uncertainty over their future associated with partial closure (Adelaide and Munich) or the recent reintroduction of the mode to what does not yet amount to a coherent network (Barcelona and Sydney). Only in Melbourne, Amsterdam, Vienna, and Zurich can there be talk of a mature, first-generation network that largely retained its significance for urban movement throughout the city. In segmental betweenness terms, this characteristic becomes manifest in double-digit percentage figures, whereas in terms of service intensity, it positions these four cities at a multiple of the operational input elsewhere. Thus, with the possible exception of Melbourne, network consolidation, service intensity and the modal share of segmental betweenness behave roughly proportionally to each other.

TABLE 2.

SNAMUTS Indicators for Tram Systems in 10 Case Study Cities

\begin{tabular}{|l|l|c|c|c|}
\hline \multicolumn{1}{|c|}{ City } & \multicolumn{1}{|c|}{ Tram } & \multicolumn{1}{c|}{$\begin{array}{c}\text { Service } \\
\text { Intensity }\end{array}$} & $\begin{array}{c}\text { Proportion } \\
\text { of Segmental } \\
\text { Betweenness }\end{array}$ & $\begin{array}{c}\text { Average } \\
\text { Network } \\
\text { Resilience }\end{array}$ \\
\hline Adelaide & First generation; single corridor & 0.8 & $5.0 \%$ & +10.6 \\
\hline Sydney & Second generation; single corridor & 0.1 & $0.8 \%$ & +1.2 \\
\hline Portland & $\begin{array}{l}\text { Second generation; selected inner } \\
\text { urban redevelopment areas }\end{array}$ & 0.5 & $2.5 \%$ & +14.3 \\
\hline Seattle & $\begin{array}{l}\text { Second generation; single inner urban } \\
\text { redevelopment area }\end{array}$ & $<0.1$ & $0.5 \%$ & +2.1 \\
\hline Barcelona & Second generation; selected corridors & 0.5 & $1.1 \%$ & +19.8 \\
\hline Munich & First generation; multiple corridors & 2.1 & $7.8 \%$ & +17.3 \\
\hline Melbourne & First generation; mature expansion & 6.7 & $30.0 \%$ & +10.4 \\
\hline Amsterdam & First generation; mature expansion & 6.3 & $16.6 \%$ & +18.1 \\
\hline Vienna & First generation; mature expansion & 10.0 & $27.8 \%$ & +17.8 \\
\hline Zurich & First generation; mature expansion & 9.0 & $21.7 \%$ & +21.7 \\
\hline
\end{tabular}

The network resilience index, however, reveals a more differentiated picture. It is conceded that aggregate measures across entire networks conceal the localized resilience performance of specific routes and corridors (see the next section for an example of a more-detailed geographical representation of this index in Hamburg) and, for the same reason, limit the scope for a meaningful comparative interpretation of results in the very small tram systems of Seattle, Portland, and Sydney. However, it becomes obvious that at a system-wide scale, the next least-resilient tram networks in the sample can be found in Australia, namely Adelaide and Melbourne. In both cities, but of particular relevance for Melbourne, trams ply some primary radial corridors which, in Munich and Vienna, would have been supplied with a metro line at some stage during the past half century. Thus, in the Bavarian and Austrian capitals, the role of trams in the modal mix has shifted as their metro networks grew, to focus more on secondary and, increasingly, orbital corridors. In Zurich, plans to build a metro did not 
come to fruition when they were rejected in favor of surface network improvements in local referenda during the 1970s (Ott 1995). However, the relatively small and compact size of the settlement area, enforced by its mountainous topography and protective spatial planning regime, ensures that the limited spatial reach of on-street tram operation remains sufficient to optimize accessibility within the core city. A higher service input in combination with a similar degree of network significance in Vienna, and a similar service input in combination with a lower degree of network significance in Amsterdam, lead to the tram systems in the Austrian and Dutch cities appearing substantially less vulnerable to the effects of current overcrowding, and capable of absorbing future patronage growth, than that of Melbourne.

\section{Case Studies: Hamburg and Munich-What If?}

To examine the impact on the resilience and vulnerability of a public transport network to potential congestion effects and its ability to accommodate further growth in patronage, the two existing public transport networks of Hamburg and Munich are assessed under scenarios that would have steered their historic evolution in a different direction. In 1958, Hamburg's city-state government decided to gradually close down the city's expansive tram network and, despite mounting public protests in the final phases of the program, followed through with it over a 20-year period (Kähler 2012). During the same period, Munich also toyed with the idea of eventually phasing out the mode and, roughly between the 1970 s and 1990 s, complemented the rapid growth of its metro system with widespread withdrawals of tram lines in the catchment of newly opened metro extensions. However, in 1986, the city council decided in favor of retaining the surviving tram routes for the long term and, since the late 1990s, embarked on a trajectory of modest network expansion (Cervero 1998). Still, as we have seen in the previous sections, Munich's much-diminished current tram network has a relatively minor role in facilitating travel opportunities around the metropolitan region compared to its larger counterparts in Amsterdam, Melbourne, Vienna, or Zurich.

This section assesses the impact on network resilience under the assumption that the two German cities' policy decisions had been reversed: What if Hamburg had retained its tram system, give or take the closure of some routes parallel to new metro lines, as well as expanded the network to access major urban development areas of the past half century? And what if Munich had, instead, decided to convert its tram network entirely to bus operation and followed through with it?

For this purpose, a hypothetical tram network was constructed for Hamburg based on the city's current network of high-frequency bus routes (Metrobus, Schnellbus, and some others) and assuming that those sections of current bus lines that follow historic tram routes were still operated by trams. In total, 14 hypothetical tram lines were identified, replicating 12 actual Metrobus lines, three Schnellbus branches, 7 regular bus lines, and fragments of several others. For service levels and capacity, it is assumed that each tram line is operated by single contemporary units (150 passengers) and at a standard 10-minute weekday inter-peak frequency (except between Lokstedt and the city center, where 5 -minute intervals prevail as on the actual bus route). Further, 
the same travel times as shown in the current bus timetable are utilized, which is a conservative assumption since it is likely that continued tram operation would have resulted in the creation or retention of a greater share of tracks on reservation, as well as traffic priority measures, than is the case along the actual bus network. All other parameters - the current expansion and configuration of the rapid rail network, service levels on other bus routes, and the distribution of land uses across the metropolitan region-are held constant. This occurs to avoid further contamination of the analysis with peripheral factors, although it stands to reason that a retained tram network in Hamburg likely would have influenced land use trends as well as rapid rail investment decisions in ways that differ from actual developments during the past six decades. A further exploration of this context would be of interest, but exceeds the scope of this paper.

In this scenario, total service intensity remains nearly identical over the status quo. As shown in Figure 2, the operational input for Hamburg's hypothetical retained tram network would be 4.8 vehicles per 100,000 population-more than twice as many than in present-day Munich, but fewer than in Amsterdam, Melbourne, Vienna, and Zurich. The number of buses, accordingly, would be reduced by a similar amount.

In terms of attracting travel opportunities generated by the land use-transport system (segmental betweenness), Hamburg's hypothetical retained tram network would absorb just under $20 \%$ of the potential transport task_far greater than in more heavyrail dominated Munich and also eclipsing Amsterdam, but trailing behind Vienna, Den Haag, and Rotterdam (Zuid Holland) as well as the metro-free agglomerations of Melbourne and Zurich.

The assumptions for this scenario, thus, do not appear out of bounds within the context of the policy directions other, comparable cities have taken. Yet, it does not represent a blueprint for the future, in the sense that the tram network constructed here was intended as a viable template for the possible reintroduction of the mode in Hamburg: it should more accurately be described as an "alternative history" scenario. 
FIGURE 2.

Service intensity

on tram network

in 11 case study

cities in vehicles per

100,000 population in

simultaneous weekday

inter-peak revenue

service, highlighting

Hamburg's

hypothetical retained

tram operation

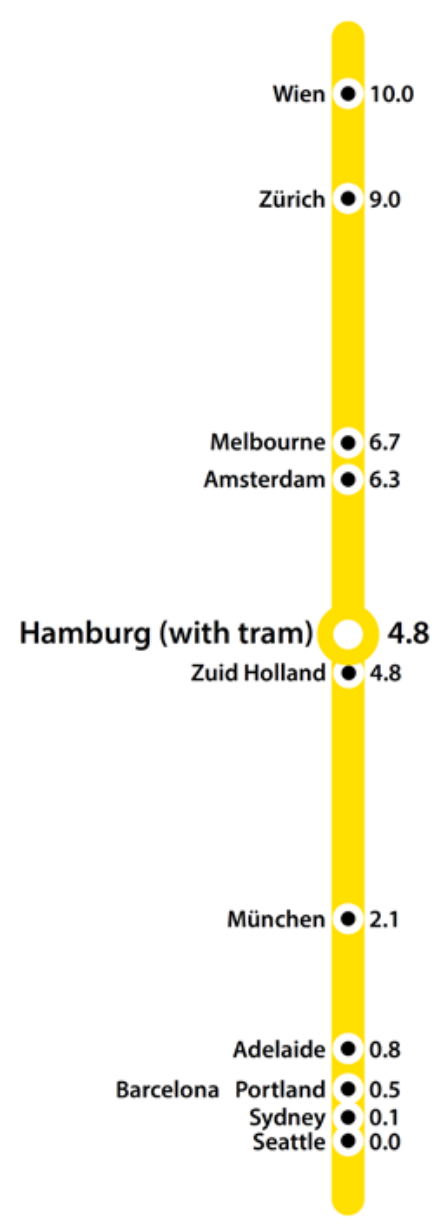

FIGURE 3.

Proportion of

metropolitan-

wide segmental

betweenness values

(travel opportunities)

attracted to tram

routes in 12 case study

cities and city-regions,

highlighting Hamburg's

hypothetical retained

tram operation

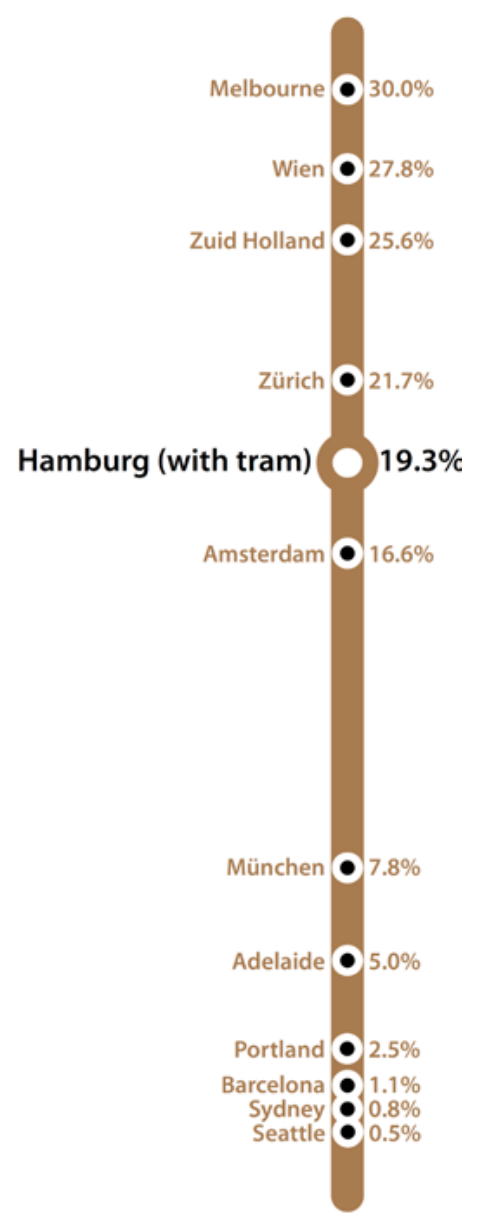

In the absence of travel time reductions through priority measures or frequency improvements compared to the actual bus lines, the main benefit of the hypothetical tram network in SNAMUTS terms will become visible in the network resilience index. This is because trams are capable of moving a significantly greater number of passengers per vehicle than buses ${ }^{1}$ and, hence, are capable of withstanding overcrowding effects and maintaining operational reliability up until a higher level of network significance, as expressed by the segmental betweenness index.

\footnotetext{
${ }^{1}$ In the Hamburg case study, we assume the comfortable passenger load per vehicle to be 150 per tram and 60 per bus, the latter representing an average across the actual fleet composition of standard, single-articulated, and double-articulated vehicles in the Hanseatic city. It is true that there is a greater likelihood for larger buses to be operated on busy routes, including some of those assumed for tram retention in this scenario. SNAMUTS does not make such differentiation (since it is not possible to obtain robust fleet deployment details on a route-by-route basis in most cities) and, thus, is likely to understate segmental resilience in some cases for the actual 2013 bus network. However, in the comparison to the tram retention scenario, the assumption of 150 passengers per tram is also relatively conservative, since larger vehicles and the practice of coupling two units into train sets are available (where the infrastructure permits) and would improve the resilience count accordingly.
} 
Figures 4 and 5 depict the distribution of network resilience performance across the Hamburg network in the 2013 status quo and in the hypothetical tram retention

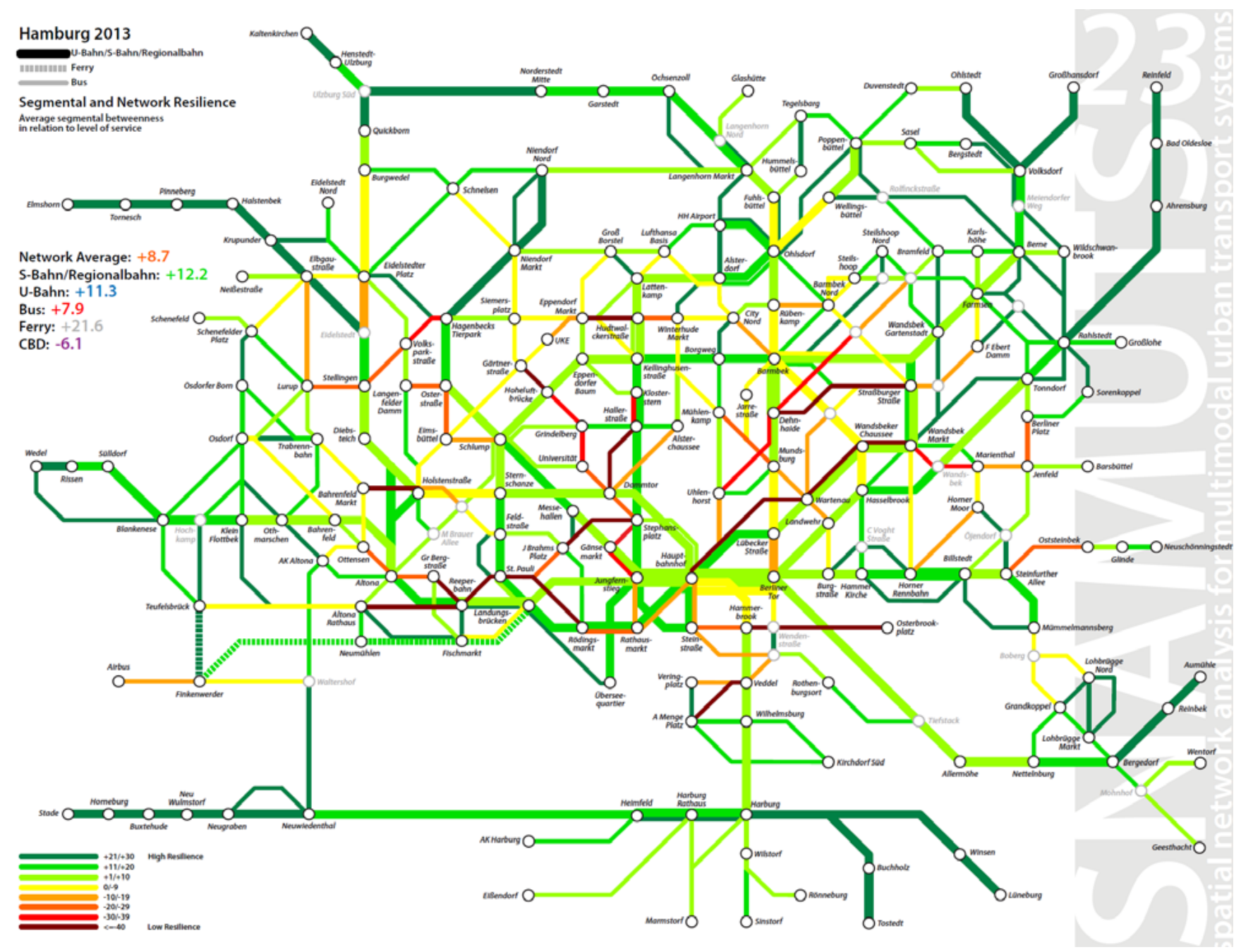

FIGURE 4. Segmental and network resilience diagram for Hamburg network in 2013 


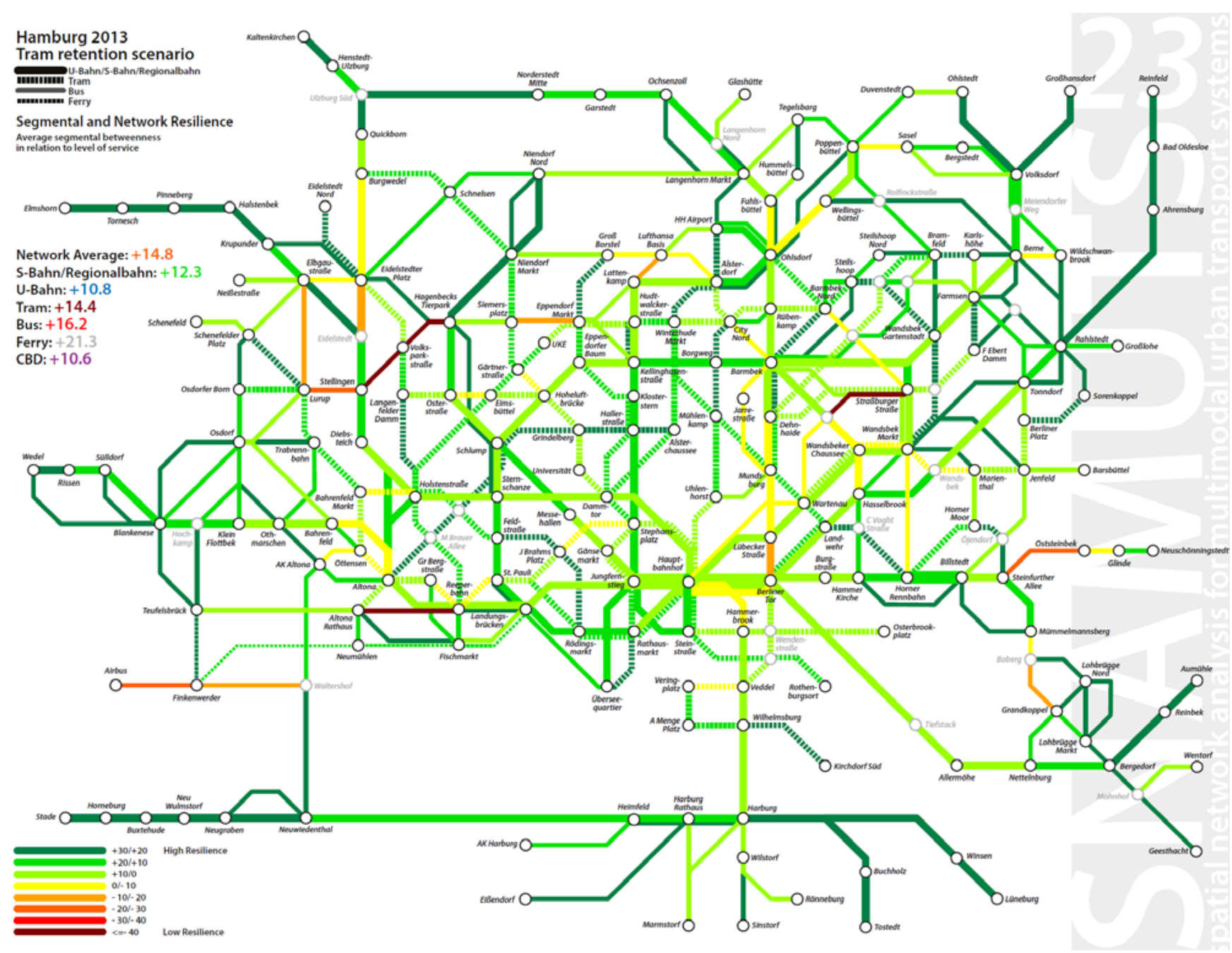

FIGURE 5. Segmental and network resilience diagram for Hamburg network in hypothetical tram retention scenario 
Average network resilience in Hamburg improves from an actual 2013 level of +8.7 to +14.8 in the tram retention scenario, similar to present-day Munich or Copenhagen and among the best performers across the SNAMUTS sample. In the CBD, whose surface public transport network is dominated by trams in the retention scenario, the average resilience value increases to +10.6 from a concerning -6.1 in the 2013 status quo network, the second poorest such value in the sample before Sydney. Figures 6 and 7 show these results in the context of the international cohort of case study cities.

\section{FIGURE 6.}

Average networkwide resilience values on public transport networks of 21 case study cities, highlighting Hamburg in 2013 status quo and tram retention scenario

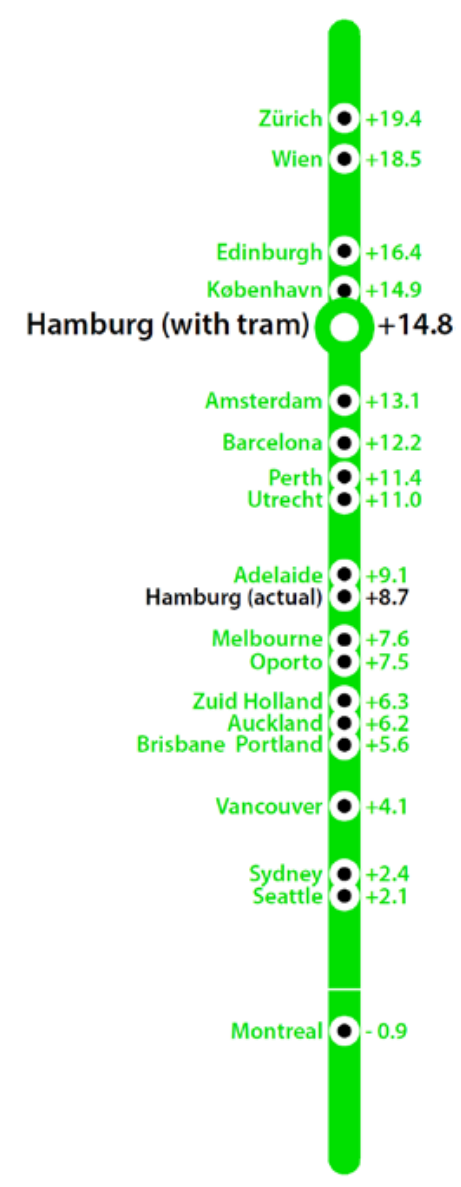

FIGURE 7.

Average resilience values on CBD proportions of public transport networks of 21 case study cities, highlighting Hamburg in 2013 status quo and tram retention scenario 
Conversely, the assessment of Munich in the hypothetical scenario of an implemented closure of the tram system (replacing the existing tram lines one-on-one by buses, with service frequencies and travel times unchanged) delivers an expected drop in resilience performance, although it is not quite as drastic as that experienced by Hamburg in real life (Figures 8 and 9). On the network-wide assessment, Munich would slip into the lower mid-field among its European peers, whereas in the CBD-specific assessment, a tram-free Bavarian capital would be exposed to greater average vulnerability when it comes to catering for travel opportunities by public transport than all other European case study cities bar Utrecht and Hamburg.

FIGURE 8.

Average networkwide resilience values

on public transport networks of 21 case study cities, highlighting Munich in 2011 status quo and tram closure scenario
FIGURE 9.

Average resilience

values on $\mathrm{CBD}$

proportions of public transport networks of

21 case study cities, highlighting Munich in 2011 status quo and tram closure scenario

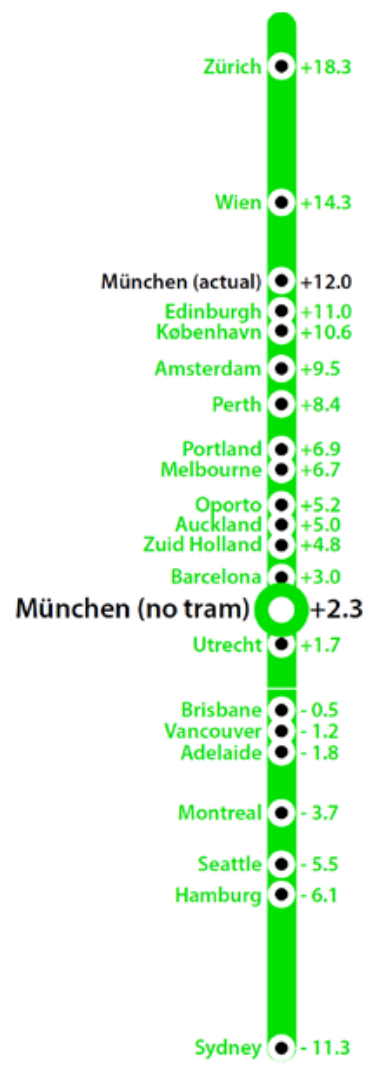


Thus, provided the resilience index itself offers the analytic robustness required for making such a statement, we can conclude that Hamburg's current precarious position in making its public transport network absorb growing passenger numbers and a growing mode share can be traced, to a significant part, to its post-war decision to replace its tram system with buses. Furthermore, this circumstance leads to a particular performance deficit in the central area where the main bus trunk routes are timetabled to saturation levels and where there is limited scope, and road space, to increase capacity by further boosting bus service frequencies. Conversely, it appears as though Munich has averted a similar crisis through its decision to preserve and modernize at least a lean core of its once-extensive tram network, and that these benefits play themselves out most impressively in the inner area where a much larger deployment of buses would be necessary to achieve a level of passenger convenience and network resilience comparable to the status quo.

\section{Discussion and Conclusions}

The intention of SNAMUTS as an accessibility tool is to assist decisionmakers in identifying visible as well as less visible shortfalls in the interplay of land use patterns and transport network performance to devise strategic interventions to enhance the position of public transport in the mobility mix of a city. In this context, the interplay of different public transport modes with varying inherent passenger capacity and operational characteristics is often a factor that is not at the forefront of public debates in each city, given that the modal distribution of transport tasks tends to be subject to a gradual, city-specific evolutionary process that is usually "taken for granted" by most stakeholders. It is also associated with the notion that the introduction of an additional transport mode and its development beyond a niche role generally represents a "generational project," requiring a vast allocation of resources as well as concerted efforts in terms of political vision, championship, and consensus-building to come to fruition. This is how Montreal, Munich, and Vienna established their metro systems at the peak of post-war modernism (Pucher and Kurth 1996; Paulhiac and Kaufmann 2006), and how Perth, Portland, and Vancouver embarked on developing leaner forms of urban rail in the emerging sustainability era (Newman and Kenworthy 1999; Schiller et al. 2010), in all cases driven by the desirability of shifting a greater share of urban transport onto rail on the grounds of city-building, efficiency, and environmental protection. It is also how Zurich, aided by the Swiss regime of direct democracy, went against the grain of conventional transport planning wisdom in the 1970s and delivered an alternative, highly-effective, and locally-adapted mix of regional and urban transport modes (Cervero 1998; Mees 2010) without resorting to the introduction of an underground metro (while building several inner-city tunnels for the regional rail system).

But such a coincidence of supportive factors towards public transport investment and modal diversification is not a global standard; in other cities, it simply failed to materialize. Hamburg is looking back on two failed attempts to reintroduce light rail since 2000 after the debate had descended into political partisanship, and the plans did 
not survive subsequent changes of government. Edinburgh opened a light rail starter line in 2014, but its further expansion has been mired in similar public controversy and remains uncertain (Karou and Hull 2014). Montreal's metro system, for all its demonstrable improvements to public transport accessibility in the core city, has expanded at a much slower than desirable rate over the past quarter century because it is technologically unsuited to operate on cheaper-to-build above-ground alignments in the harsh Québec winter. Vancouver's SkyTrain is on track to become a victim of its own success in instilling a "public transport culture" in the British Columbian city, likely necessitating expensive retrofits to increase its passenger capacity in the future (Curtis and Scheurer 2016). In each of these examples, we can detect patterns of path dependency that inhibit or slow down efforts to further enhance public transport, whether for reasons of transport technology or for factors to do with the course of political debates specific to each city (Curtis and Low 2012).

Against this background, is it even practically helpful to make comparisons between public transport performance in cities that have, for many decades, embarked on different trajectories that cannot be modified easily or within the time frames that determine the horizons of political decisionmakers?

The analysis undertaken in this paper asserts that there is a role for a benchmarking process that can point out what constitutes international best practice in public transport accessibility and serve as a guide for cities to inform their transport and land use planning practice with the aid of quantification tools such as SNAMUTS. The purpose of such a process is not to merely lament-to use our case study example-the standard of accessibility performance that Hamburg failed to achieve but could have achieved had it followed the public transport development policies of Amsterdam, Munich, or Vienna over the past half-century. Rather, it is about unleashing the creativity of policymaking as demonstrated, for instance, by Zurich since the 1970s in exploring alternative futures that lead to comparable or superior outcomes in accessibility terms than what the conventional strategies of cities with greater resources or less political contention are able to deliver.

\section{Acknowledgment}

Field research in the 19 case study cities was made possible by Australian Research Council (ARC) Discovery Grant DP110104884, 'spatial Network Analysis for Multimodal Urban Transport Systems: A Planning Support Tool."

\section{References}

Cervero, R. 1998. The Transit Metropolis. A Global Inquiry. Washington, DC: Island Press.

Curtis, C., and N. Low. 2012. Institutional Barriers for Sustainable Transport. Aldershot, UK: Ashgate.

Curtis, C., and J. Scheurer. 2010. "Planning for Sustainable Accessibility: Developing Tools to Aid Discussion and Decision Making." Progress in Planning, 74(2):53-106. 
Curtis, C., and J. Scheurer. 2016. Planning for Public Transport Accessibility. Oxon, UK: Routledge.

Freeman, L. C. 1977. "A Set of Measures of Centrality Based on Betweenness." Sociometry, 40(1): 35-41.

Griffin, T. 2005. "Public Transport - Mode Options and Technical Solutions." HiTrans Best Practice Guide 4, Civitas Consultants, Oslo, Norway.

Hass-Klau, C., G. Crampton, C. Biereth, and V. Deutsch. 2003. “Bus or Light Rail: Making the Right Choice. A Financial, Operational, and Demand Comparison of Light Rail, Guided Buses, Busways, and Bus Lanes." Government of the United Kingdom, Environmental and Transport Planning, London/Brighton, UK.

Kähler, G. 2012. “Auto, Straße und Verkehr: Vom Freiheitsversprechen zum Stau. Part 1.” In Frank, H., and U. Schwarz, eds., Die Stadt und das Auto. Wie der Verkehr Hamburg veränderte. Hamburg, Germany: Dölling und Galitz Verlag,

Karou, S., and A. Hull. 2014. "Accessibility Modelling: Predicting the Impact of Planned Transport Infrastructure on Accessibility Patterns in Edinburgh, UK." Journal of Transport Geography, 35: 1-11.

Koschützk,i D., K. A. Lehmann, L. Peeters, S. Richter, D, Tenfelde-Podehl, and O. Zlokowski. 2005. "Centrality Indices." Chapter 3 in Brandes, U., and T. Erlebach, eds., Network Analysis: Methodological Foundations. Lecture Notes in Computer Science, No 3418. Berlin/Heidelberg: Springer.

Mees, P. 2010 Transport for Suburbia: Beyond the Automobile Age. London, UK: Earthscan.

Newman, P., and J. Kenworthy. 1999. Sustainability and Cities. Overcoming Automobile Dependence. Washington DC: Island Press.

Ott, R. 1995. "Conurbation Transport Policy in Zurich, Switzerland." Proceedings of the Institution of Civil Engineers, 111(3): 225-233.

Paulhiac, F., and V. Kaufmann. 2006. "Transports Urbains à Montréal: Evolution des Référentiels et Enjeux d"une Politique Durable." Revue d"Economie Régionale et Urbaine, 1: 49-80.

Porta, S., P. Crucitti, and V. Latora. 2006. "The Network Analysis of Urban Streets: A Primal Approach." Environment and Planning B: Planning and Design, 33: 705-725.

Pucher, J., and S. Kurth. 1996. "Verkehrsverbund: The Success of Regional Public Transport in Germany, Austria and Switzerland." Transport Policy, 2(4): 279-91.

Scheurer, J., C. Curtis, and S. Porta. 2007. 'spatial Network Analysis of Public Transport Systems: Developing a Strategic Planning Tool to Assess the Congruence of Movement and Urban Structure in Australian Cities." 30th Australasian Transport Research Forum (ATRF), Melbourne, September.

Schiller, P. L., E. Bruun, and J. R. Kenworthy. 2010. An Introduction to Sustainable Transportation. Policy, Planning and Implementation. London, UK: Earthscan. 
Shimbel, A. 1953. "Structural Parameters of Communication Networks." Bulletin of Mathematical Biophysics, 15: 501-507.

Van der Bijl, R., and N. Van Oort. 2014. Light Rail Explained: Better Public Transport and More than Public Transport. European Metropolitan Transport Authorities (EMTA), Amsterdam/Delft, Netherlands.

Vuchic, V. R. 2005. Urban Transit: Operation, Planning and Economics. Hoboken, NJ: Wiley.

\section{About the Author}

DR. JAN SCHEURER (jan.scheurer@rmit.edu.au) is a Senior Research Fellow at Curtin University, Perth and RMIT University, Melbourne/Barcelona. He is the principal designer of the Spatial Network Analysis for Multimodal Urban Transport Systems (SNAMUTS) accessibility tool and researches in the fields of accessibility planning, urban design, sustainability policy, and mobility culture. 